\title{
Advance Technique to Increase Production from Tight Formations Using HiWAY Flow-Channel Hydraulic Fracturing Technique
}

Ahammad Sharif MD*, Nagalakshmi NVR, Srigowri Reddy S, Vasanth G and Uma Sankar K

Department of Petroleum Engineering, GIET College of Engineering, Rajahmundry, Andhra Pradesh, India

\begin{abstract}
Hydraulic fracturing treatments are accomplished to create a highly conductive flow path from the reservoir to the wellbore. Maximum success requires stimulating all perforation in the treated interval. However, performing such coverage is challenging in unconventional reservoirs because fracture opening pressures can vary widely within the perforated interval. A new fracturing service that employs an innovative diverting agent improves production from established fields and allows operators to develop areas that previously were not economically viable. HiWAY flowchannel fracturing technique specially increases fracture conductivity. It has also been proven to lower the risk of the screen out (premature job termination because of rapid pressure increase produced by a sudden flow restriction), allowing jobs to be placed more reliably. On average, the HiWAY fracturing technique increases production more than $20 \%$, while usage $40 \%$ less prop pant. Moreover, compared with slick water treatments, the technique can use up to $25 \%$ less water. The result is higher short and long-term production, simplified logistics, a smaller operational footprint, and significantly reduced environmental impact. This paper is going to discuss about the hydraulic fracture process, reason of hydraulic fracturing, new technique i.e., HiWAY Flow-Channel Fracturing technique, and the results of two well stimulation treatment which was done through the HiWay flow-channel Fracturing technique, that proving the increase of oil production over extended periods even with decreasing reservoir pressure near wellbore.
\end{abstract}

Keywords: HiWAY flow-channel; Fracturing technique; Oil and gas reservoir

\section{Introduction}

As oil and gas production from the tight formations which is having the ultra-low permeability in commercial rates for large periods of time, find a bit difficult with the current stimulation technologies which used in the industry right now. Normally, Hydraulic Fracturing processes are performed to create a highly conductive flow path from the reservoir to the wellbore. Maximize effectiveness requires stimulating all perforations in the treated interval. To achieving such coverage is challenging in unconventional reservoirs because fracture initiation pressures can vary widely within the perforated interval.

Normal, Hydraulic fracturing with conventional techniques is a practice to enhance conductivity which has been directed at improving the ability of oil and gas to flow through a porous prop pant pack. As industry use fracturing technique to create fractures in the reservoir for making a path to hydrocarbon so that they can easily flow from the reservoir to the surface. Now, industry has focused towards the goal of increasing prop pant pack permeability by developing less damaging carrier-fluids, more coherent fracturing fluid breakers, higher strength man-made prop pants etc. but no certainty of maintaining long-term production.

The concept of the HiWAY flow-channel hydraulic fracturing technique is to design flow paths inside the prop pant porous media to give infinite flow conductivity, which delivers a number of significant benefits: greater effective contact area, lowered risk of screen-out, lowered artificial lift cost, reduced well completion time and cost, lower pressure loss within the fractures which leads towards improved short and long-term production (Figure 1).

\section{Reason for doing hydraulically fracture in oil and gas reservoir}

- The basis of hydraulic fracturing an oil or gas reservoir is to permit the oil or gas to flow more easily from the formation to the wellbore, and this process is known as stimulation.
- Remaining reservoir today requires some sort of stimulation treatment to be able to bring production rates to economic levels.

- In conventional oil and gas reservoirs usually have interconnected pathways within the rock matrix that allow the hydrocarbons flow to the wellbore, sometimes without stimulation.

- In unconventional reservoirs, often the grain size of the rock matrix is much smaller and the pores are poorly to connected, in these types of reservoirs, while there are significant quantities of hydrocarbons trapped in the rock matrix, there are limited connected pathways that allow the hydrocarbons to influx.

- The process of hydraulic fracturing is designed to produce fractures or connect to existing fractures within the reservoir thus creating a pathway by which the hydrocarbons can flow to the wellbore (Figure 2).

\section{Type of fracturing depending on number of variables}

- Type of wells that has been drilled (vertical or horizontal)

- Rock properties of the potential reservoir

- Depth, thickness, pressure and temperature of the reservoir

- Well construction-type of wellbore casing and cementing

- Number of fractures to be completed in the wellbore

*Corresponding author: Ahammad Sharif MD, Department of Petroleum Engineering, GIET College of Engineering, Rajahmundry, Andhra Pradesh, India Tel: +919603056177; E-mail: ahmedsharif.chem95@gmail.com

Received March 30, 2017; Accepted April 03, 2017; Published April 05, 2017

Citation: Sharif MDA, Nagalakshmi NVR, Reddy SS, Vasanth G ,Uma Sankar K (2017) Advance Technique to Increase Production from Tight Formations Using HiWAY Flow-Channel Hydraulic Fracturing Technique. J Adv Chem Eng 7: 165. doi: $10.4172 / 2090-4568.1000165$

Copyright: (c) 2017 Sharif MDA, et al. This is an open-access article distributed under the terms of the Creative Commons Attribution License, which permits unrestricted use, distribution, and reproduction in any medium, provided the original author and source are credited. 
Citation: Sharif MDA, Nagalakshmi NVR, Reddy SS, Vasanth G, Uma Sankar K (2017) Advance Technique to Increase Production from Tight Formations Using HiWAY Flow-Channel Hydraulic Fracturing Technique. J Adv Chem Eng 7: 165. doi: 10.4172/2090-4568.1000165

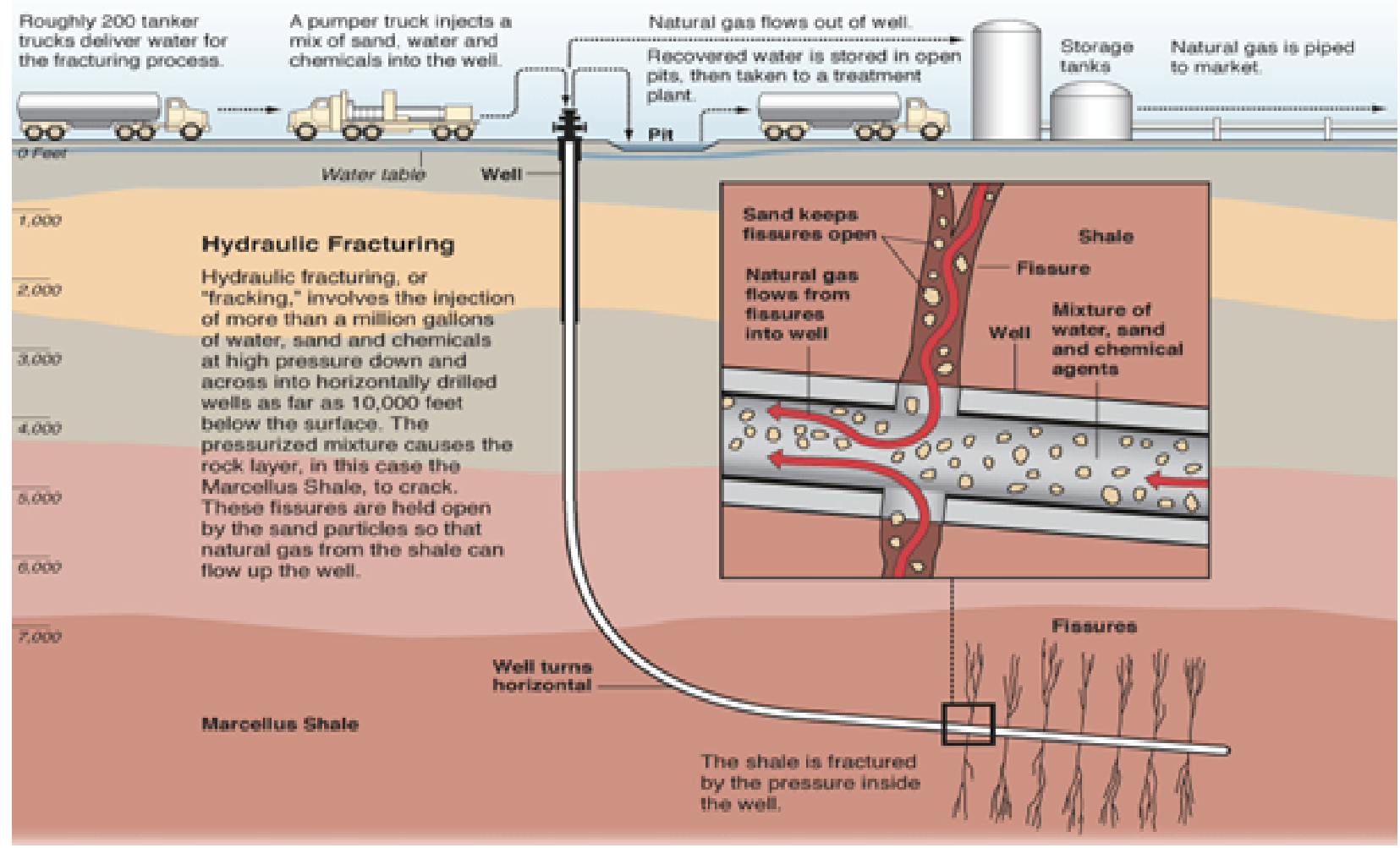

Figure 1: HiWAY flow-channel hydraulic fracturing technique.

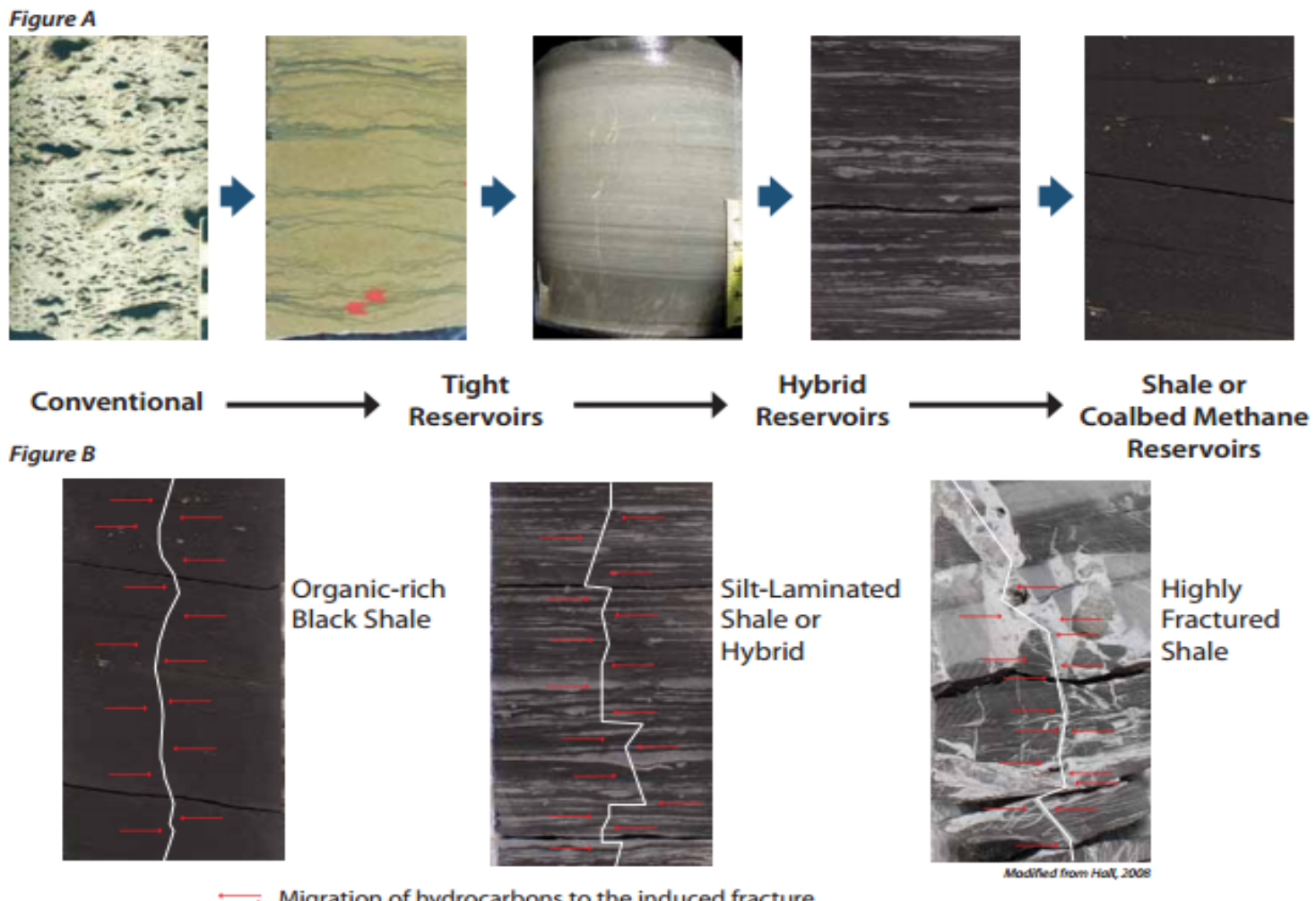

Figure 2: Migration of hydrocarbons to the induced fracture. 
- Choice of fracturing fluids and materials

- Cost of fracturing and materials.

\section{Process of hydraulic fracturing}

- Pressure the reservoir rock using a fluid to create a fracture

- Grow the fracture by containing to pump fluids into the fractures

- Pump prop pant materials into the fracture in the form of a slurry, as part of the fracture fluid

- Stop pumping and flow back to the well to recover the fracture fluids while leaving the prop pant in place in the reservoir.

\section{Materials and Methods}

\section{Techniques used in hydraulic fracturing}

- HFM (Hydraulic Fracture Monitoring) Technique

- Hi-Way (Flow-Channel) Technique.

HFM (hydraulic fracture monitoring) technique: In an effort to better characterize hydraulic fracture behaviour and geometry away from the wellbore, two HFM techniques have proved enormously successful.

The far-field fracture-mapping methods are:

\section{A) Surface and down-hole tilt meters}

- Tilt-meters measure small changes in earth tilt.

- When these are mapped they show the distortion in result to the creation of hydraulic fractures.

- Tilt-meters can be situated on surface or down hole in a monitoring wellbore (Figure 3).

\section{B) Micro-seismic monitoring}

- Micro-seismic monitoring uses sensitive, multi-component sensors in monitoring wells to record micro-seismic events, or acoustic emissions (AEs), caused by rock shearing during hydraulic fracture treatments.

- The micro-seismic data are then processed to determine the distance and azimuth from the receiver to the $\mathrm{AE}$ and the depth of the AE (Figure 4).

Hi-Way (Flow-Channel) technique: It is the strategies for improving fracture production by optimizing conductivity have traditionally included

- Enhanced prop pant roundness and strength

- Lowering prop pant crush and gel loadings

- Improve gel breakers.

These strategies are all based on improving flow through a porous prop pant or sand pack (Figure 5). It redefines hydraulic fracturing by detaching the link between fracture flow and prop pant conductivity and gains what other fracture techniques cannot-Infinite fracture conductivity (Figure 6).

Features of Hi-Way: The Features of HiWAY which make this technique so different from conventional fracturing technique are as follow:

\section{- No conductivity losses}

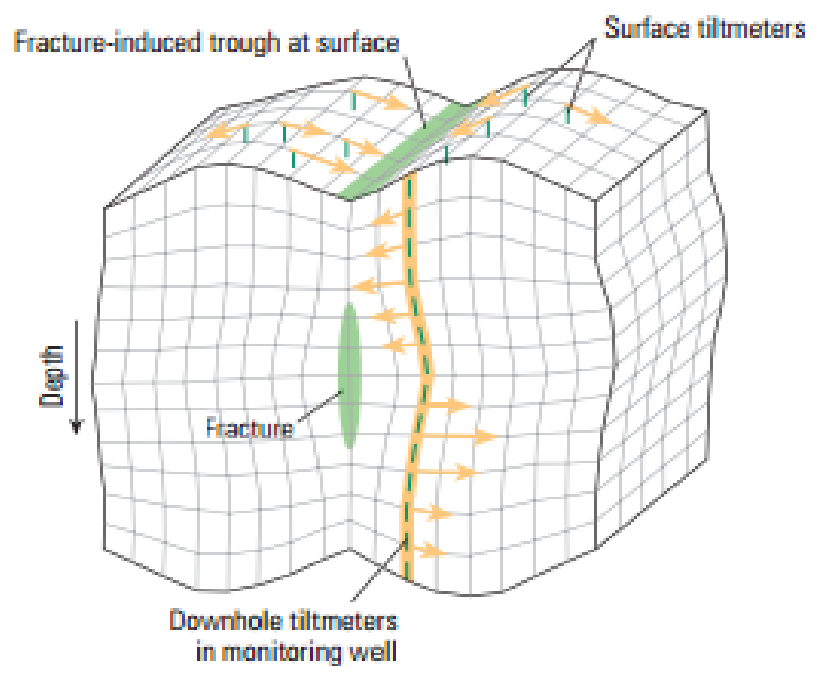

Figure 3: Surface and down-hole tilt meters.

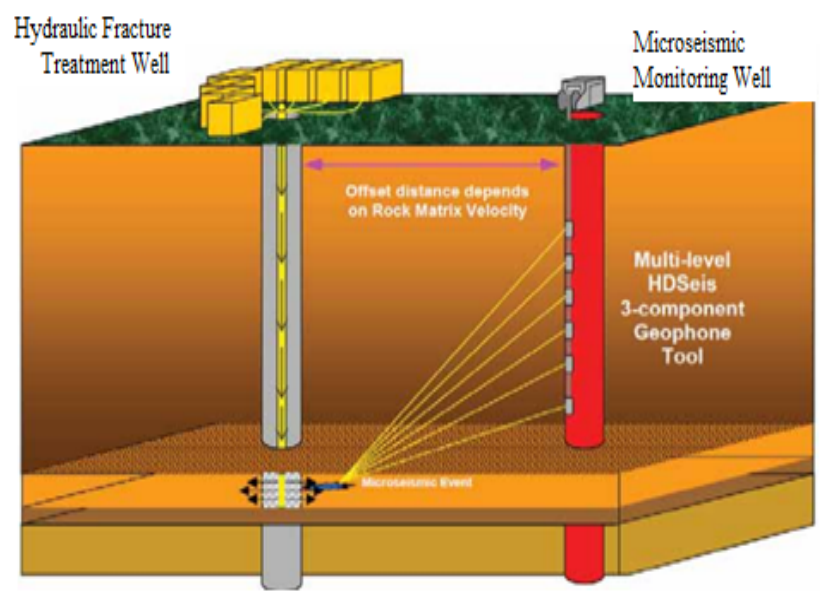

Figure 4: Micro-seismic Hydraulic Fracture Monitoring Technique.

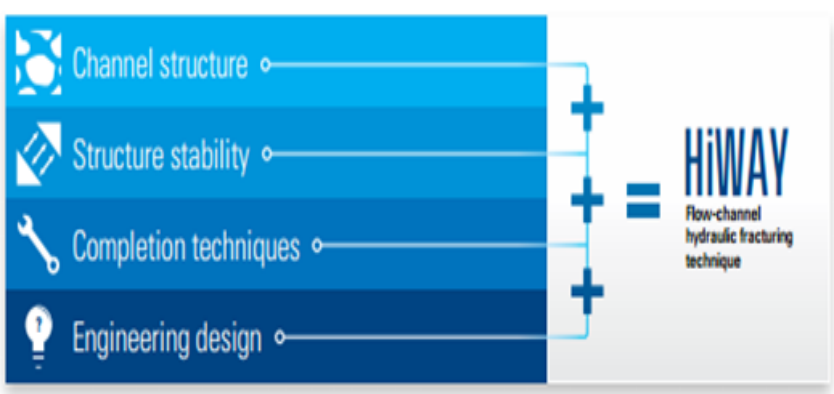

Figure 5: A unique combination of placement, materials and engineering allows the HiWAY technique to completely change the face of Hydraulic Fracturing

- Flow-channel creation

- Combination of disciplines 


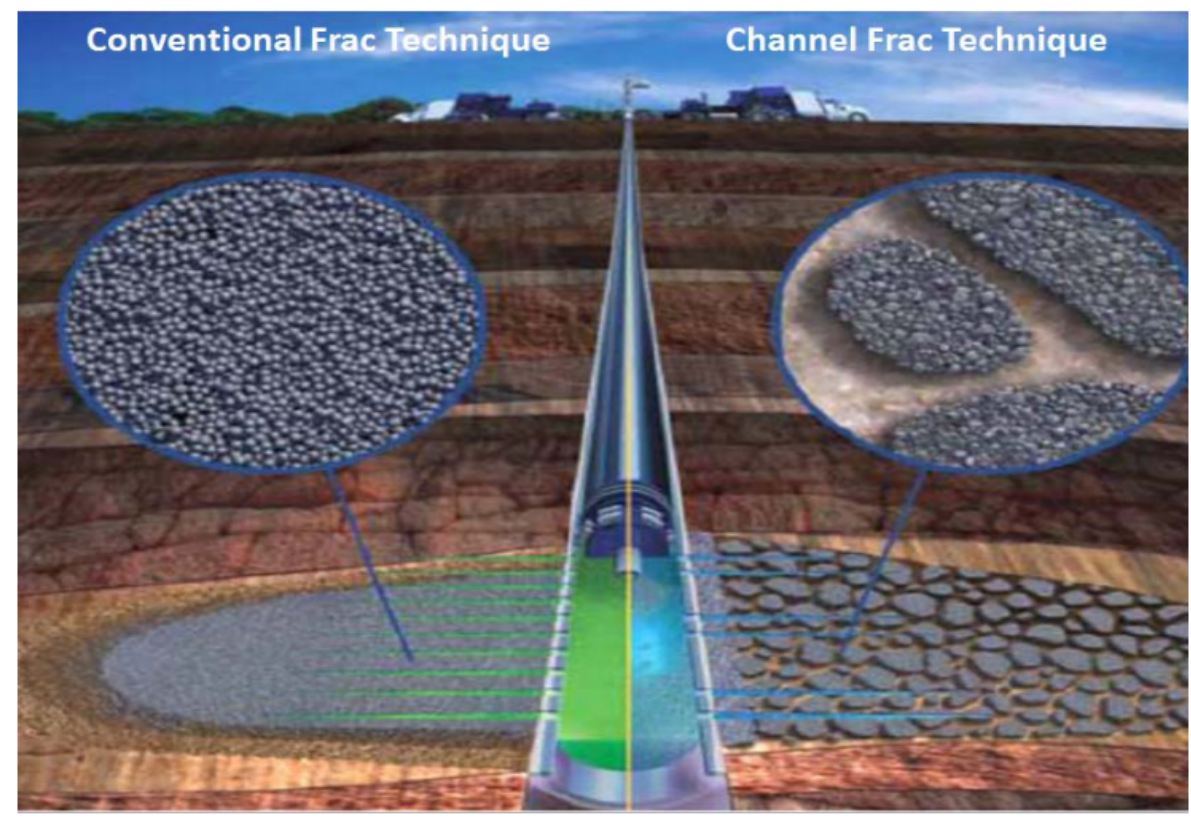

Figure 6: The Comparison between conventional fracturing and channel fracturing technique.

- Longer effective fracture half-length

- Lower pressure along the fracture for higher reservoir pressure to the wellbore

- Enhanced fluid and polymer recovery

- Less fracture face damage.

\section{Economic evaluation}

- Consolidated rock fracturing treatments

- Single and multistage, vertical and horizontal oil and gas wells

- Formation temperatures from 100 to $300^{\circ} \mathrm{F}$ (Figure 7).

\section{Benefits}

- Improved production through infinite fracture conductivity and greater effective contact area

- Lowered risk of screen-out

- Lowered artificial lift cost

- Reduced well completion time and cost (Figure 8).

\section{Results and Discussion}

\section{Case studies that proved the effectiveness of HiWAY channel fracturing}

Case -1, Well G-3: Well G-3 well was drilled and with the help of log data (see below figure) was not too confident about the accumulation of oil at Bahariya formation and also with the help of MDT shows very low mobility around $0.01 \mathrm{mD} / \mathrm{cp}$ only (Figure 9 ).

The well was decided to test after perforation by lifting with nitrogen and still after that production was zero, however, reservoir pressure was approx. 3,000 psi. With the help of the channel fracturing technique, the well was stable at 500 BOPD flow rate with a constant bottom hole

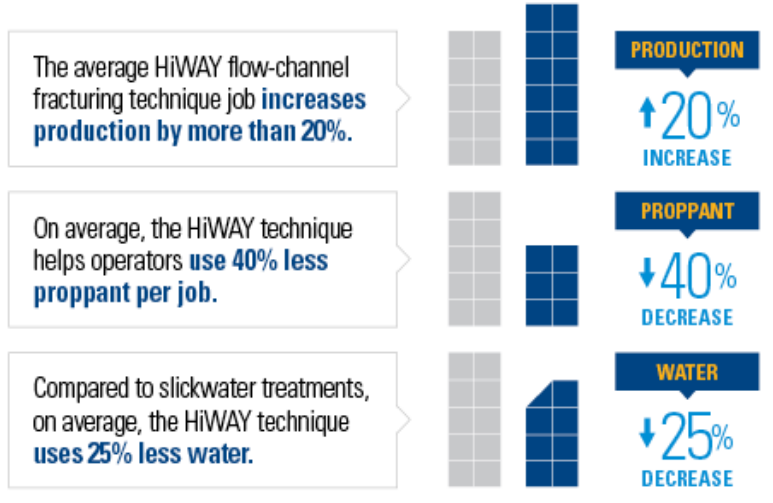

Figure 7: Economic Evaluation Hi-Way (Flow-Channel) Technique.

flowing pressure. After increasing pump capacity with the help of workover operation, the production of the well reaches around 700 BOPD as shown in the Figure 10 below.

Case - 2, Well S-2: At the time of drilling, this well finds some mechanical problems in the wellbore and due to this the open-hole log suite was cancelled with 7" casing being run directly. Then a plan was made to be taken to perforate the lower Abo Roash 'G'formation and test with the help of nitrogen; this made in zero production. Although that the channel fracturing technique is used to stimulate the well, which results in the production of well more than 1,000 BOPD, as shown in the Figure 11 below.

As from all the above cases, it is worth to say that there was $20 \%$ decrease in horsepower requirements in channel fracturing treatment as compared to conventional fracturing technique and also flow back of the post-frac fluid is increased by $25 \%$, compared with conventional fracturing treatment [1-13]. 
Citation: Sharif MDA, Nagalakshmi NVR, Reddy SS, Vasanth G, Uma Sankar K (2017) Advance Technique to Increase Production from Tight Formations Using HiWAY Flow-Channel Hydraulic Fracturing Technique. J Adv Chem Eng 7: 165. doi: 10.4172/2090-4568.1000165

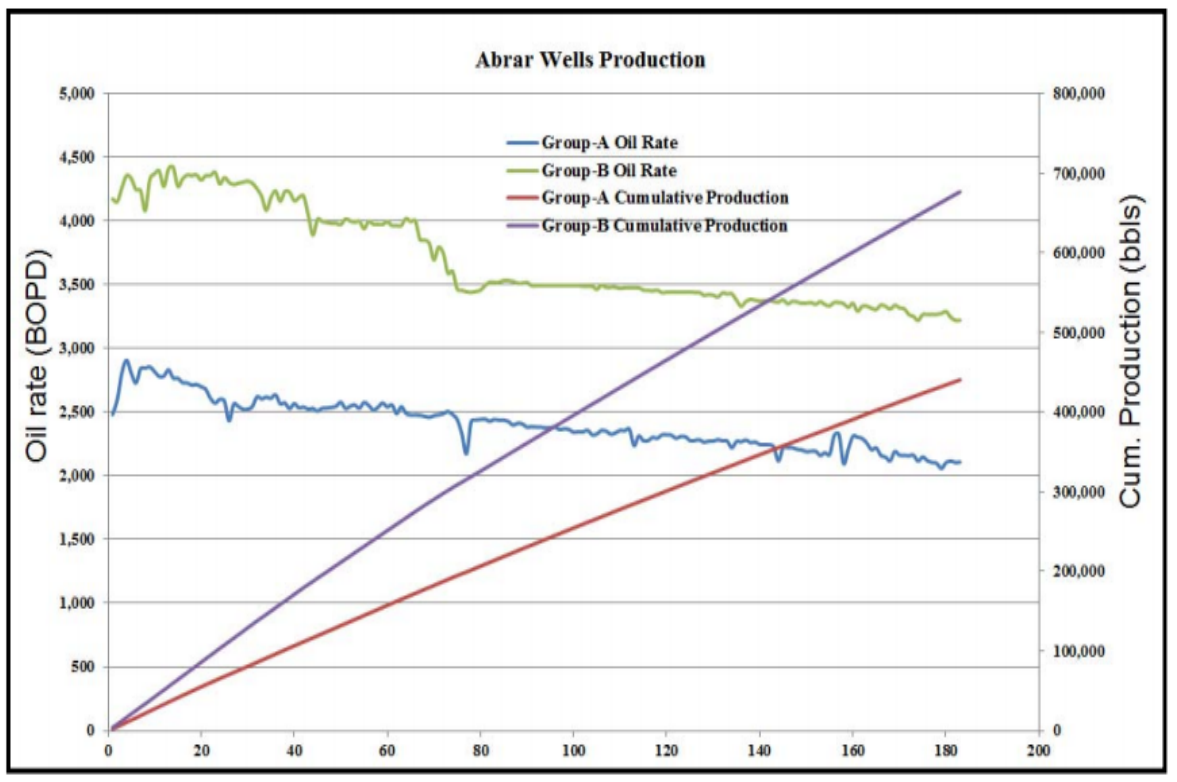

Figure 8: Production performance comparison between conventional and channel fracturing techniques

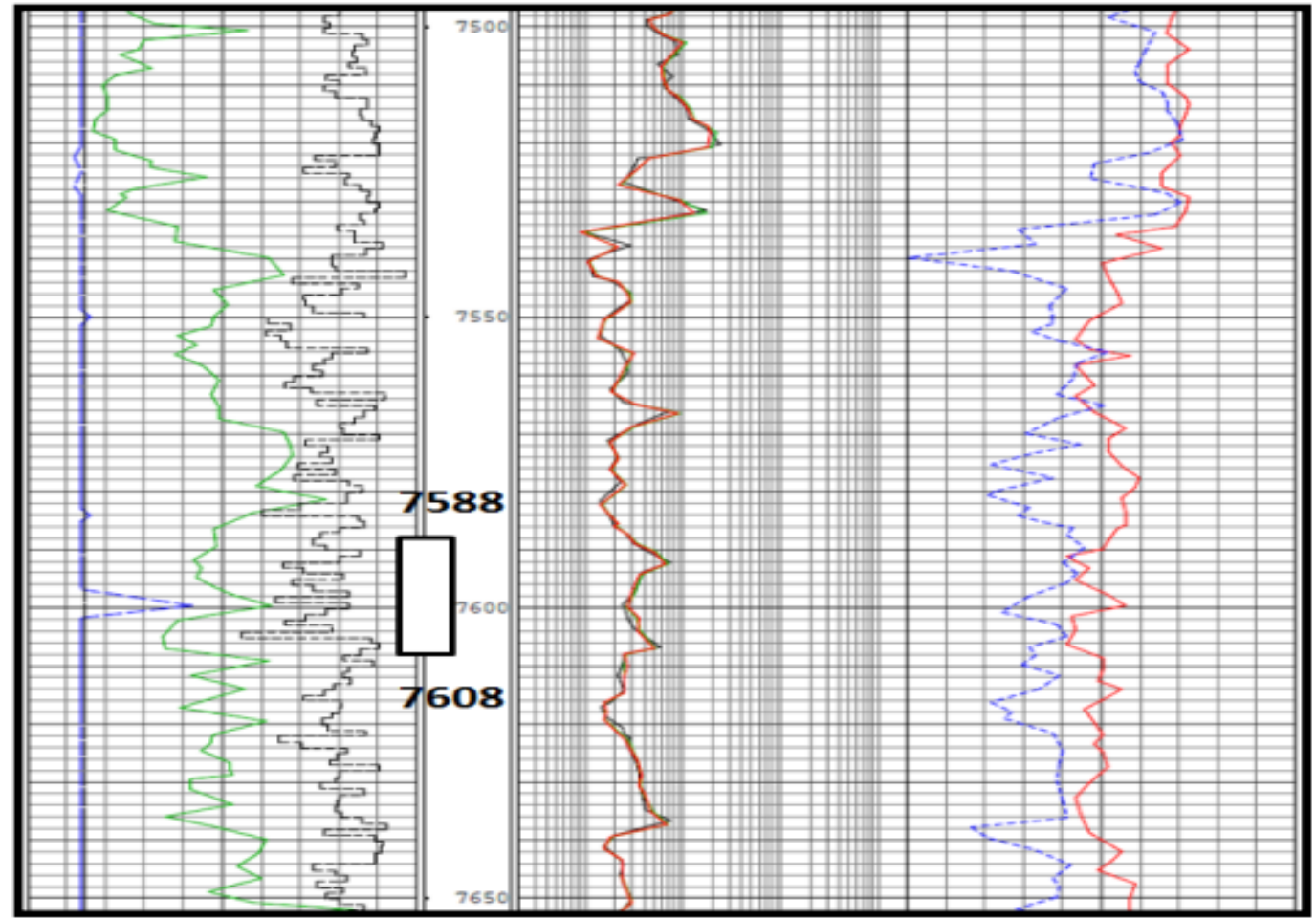

Figure 9: Well G-3 log.

\section{Reliability of this technique}

- Of the more than 11,400 horizontal wells in the Eagle Ford Shale, more than 1,100 liquid- and gas-producing wells have been completed using the HiWAY flow-channel fracturing technique (blue) since October 2010
- Till today approximately 1800 HiWay jobs are executed nearly in 15 numbers of countries.

\section{Conclusion}

HiWAY technology is use for optimizing fracture conductivity and operational efficiency without increasing water cut in the remote field. 
Citation: Sharif MDA, Nagalakshmi NVR, Reddy SS, Vasanth G, Uma Sankar K (2017) Advance Technique to Increase Production from Tight Formations Using HiWAY Flow-Channel Hydraulic Fracturing Technique. J Adv Chem Eng 7: 165. doi: 10.4172/2090-4568.1000165

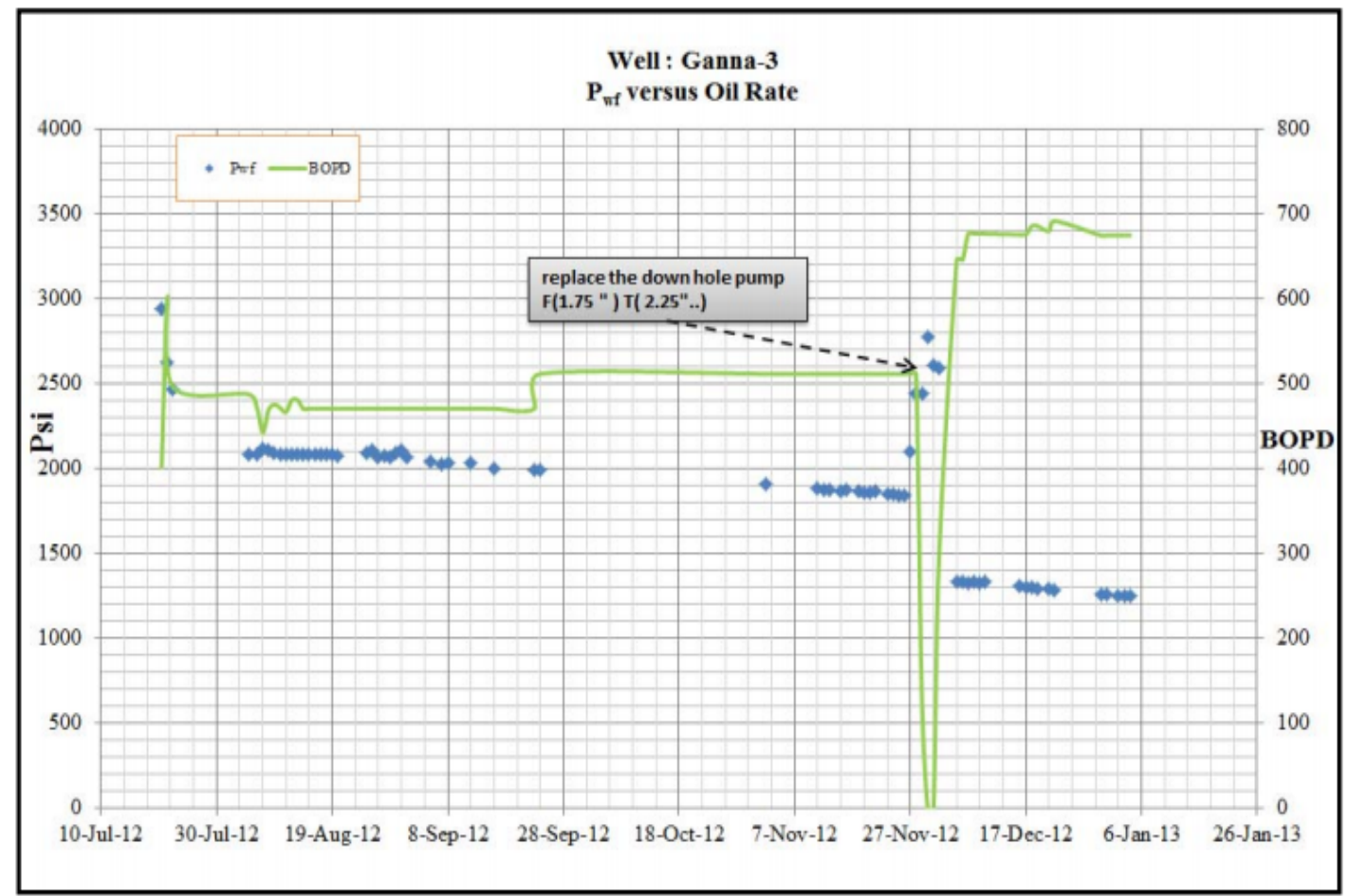

Figure 10: Well G-3 performance.

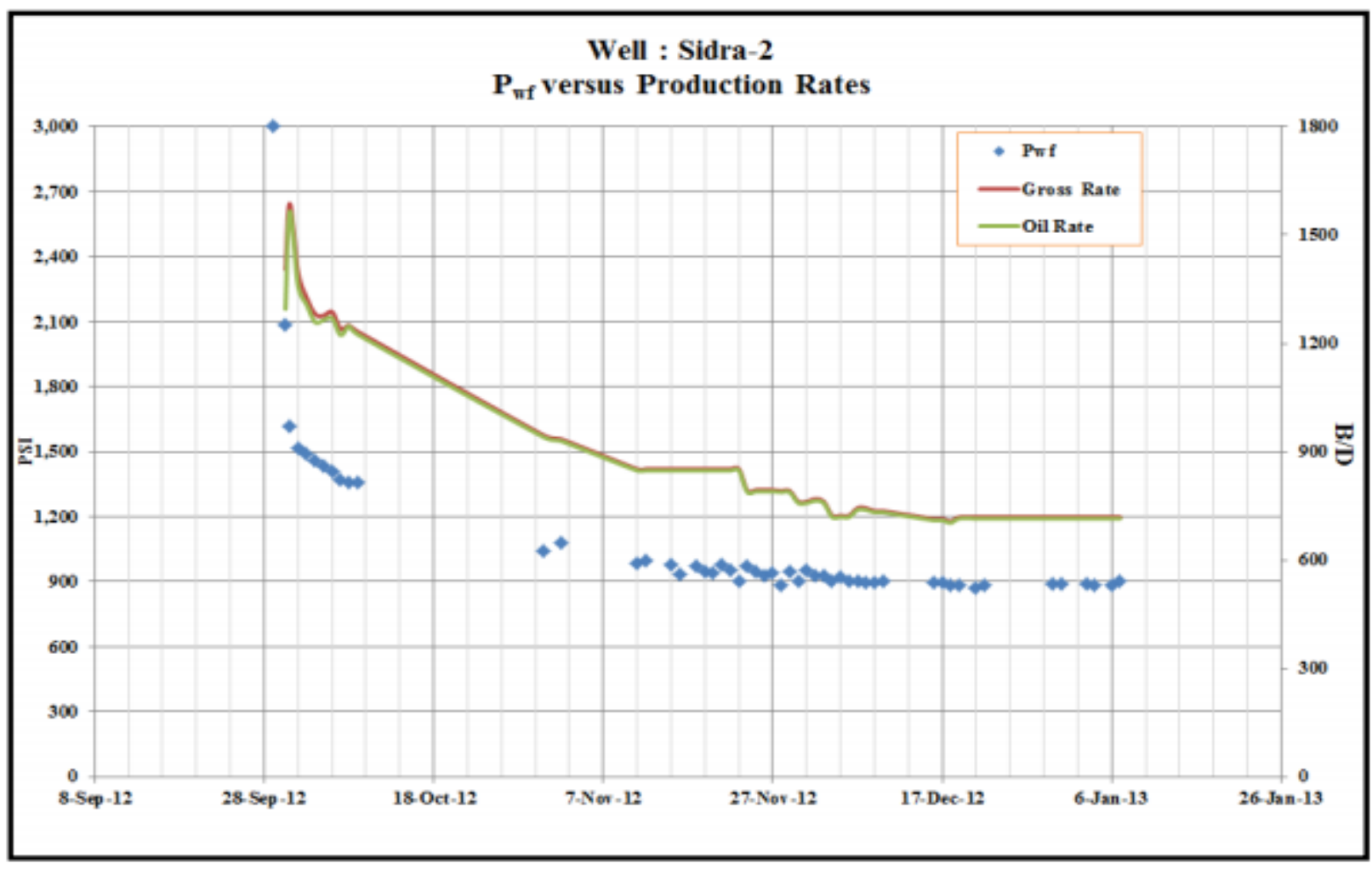

Figure 11: Well S-2 Performance. 
Citation: Sharif MDA, Nagalakshmi NVR, Reddy SS, Vasanth G, Uma Sankar K (2017) Advance Technique to Increase Production from Tight Formations Using HiWAY Flow-Channel Hydraulic Fracturing Technique. J Adv Chem Eng 7: 165. doi: 10.4172/2090-4568.1000165

With this HiWay technology, we are able to speed flow back, improve clean-up, increase effective fracture half-length, and reduce the risk of screen-outs. And with the help of this technique, which was been designed by a multinational service company, can also adopt in INDIA to enrich hydrocarbon exploration with less investment.

\section{References}

1. Samir SPEM (2013) Sahara Oil and Gas Company: Novel Technique to Increase Production from Tight Reservoirs using Channel Fracturing Technique for the First Time in the Middle East and North Africa, Paper SPE 164655 Presented at the North Africa Technical Conference Exhibition held in Cairo, Egypt, pp: 15-17

2. Samir M, Kamal SPEM, Mathur A, Semary M, Yosry M, et al. (2013) Sahara Oil \& Gas Company: Production Enhancement in the Egyptian Western Desert using the Channel Fracturing Technique - A Field Case Study, Paper SPE 164709 presented at the North Africa Technical Conference Exhibition held in Cairo, Egypt, pp: 15-17.

3. Chad K, Bruno L, Pablo P, Ariel V, Hunter W (2014) Unlocking the Potential of Unconventional Reservoirs. Oilfield Review 26: 4-17.
4. Barry B, Jack E, Mark M, Hugo M, Ken N, et al. (1992) Cracking Rock: Progress in Fracture Treatment Design. Oilfield Review 4: 4-17.

5. Les B, Joel Le C, David R, Sarver KT, Birk GW, et al. (2005) The Source for Hydraulic Fracture Characterization. Oilfield Review 17: $42-57$.

6. http://www.csur.com/images/CSUG_publications/CSUG_HydraulicFrac_ Brochure.pdf

7. http://www.slb.com/resources/publications/industry articles/ stimulation/201212_harts_hydraulic_fracturing_key_players.aspx

8. www.halliburton.com/public/pinnacle/contents/Case_Histories/web/H08441.pdf

9. https://www.propublica.org/special/hydraulic-fracturing-national

10. http://www.slb.com/services/completions/stimulation/sandstone/hiway_ channel_fracturing.aspx

11. www.slb.com/HiWAY

12. https://en.wikipedia.org/wiki/Hydraulic_fracturing_in_Canada

13. https://en.wikipedia.org/wiki/Hydraulic_fracturing 